\begin{tabular}{|c|c|c|c|}
\hline \multirow{2}{*}{$\begin{array}{r}\text { Case Reports in } \\
\text { Gastroenterology }\end{array}$} & \multicolumn{2}{|c|}{ Case Rep Gastroenterol 2019;13:140-143 } & \multirow[b]{2}{*}{$\begin{array}{l}\text { Karger } \\
\text { Open access }\end{array}$} \\
\hline & $\begin{array}{l}\text { DOI: } 10.1159 / 000499181 \\
\text { Published online: March 29, } 2019\end{array}$ & $\begin{array}{l}\text { (c) } 2019 \text { The Author(s) } \\
\text { Published by S. Karger AG, Basel } \\
\text { www.karger.com/crg }\end{array}$ & \\
\hline & $\begin{array}{l}\text { This article is licensed under th } \\
\text { International License (CC BY-NC } \\
\text { Usage and distribution for comme }\end{array}$ & $\begin{array}{l}\text { nons Attribution-NonCommerci } \\
\text { ger.com/Services/OpenAccessLic } \\
\text { uires written permission. }\end{array}$ & \\
\hline
\end{tabular}

\title{
Resected Intrahepatic Cholangiocarcinoma with Anaphylactic Shock from a Preoperative Liver Function Test before Hepatectomy
}

\author{
Kazuhiro Higuchi Atsushi Nanashima Masahide Hiyoshi \\ Naoya Imamura Koichi Yano Takeomi Hamada Yuki Tsuchimochi \\ Takashi Wada Kazuyo Tsuchiya Fumiaki Kawano Takuto Ikeda \\ Shinsuke Takeno \\ Division of Hepatobiliary-Pancreatic, Gastrointestinal, Endocrine and Pediatric Surgery, \\ Department of Surgery, University of Miyazaki Faculty of Medicine, Miyazaki, Japan
}

\section{Keywords}

Indocyanine green test · Anaphylaxis - Intrahepatic cholangiocarcinoma · Hepatectomy

\begin{abstract}
The indocyanine green test is a reliable liver function examination before major hepatectomy, and anaphylaxis is rarely a concern. A 65-year-old male patient without epigastralgia was diagnosed with a $2.2-\mathrm{cm}$ intrahepatic cholangiocarcinoma. He had no history of allergic reactions. Some liver dysfunction was indicated by the laboratory data; however, there was no marked obstructive jaundice and the liver functional reserve was maintained by technetium$99 \mathrm{~m}$ galactosyl serum albumin. The indocyanine green test was routinely performed, but the patient immediately demonstrated severe anaphylaxis due to indocyanine green administration. He had cardiorespiratory arrest, but recovered after immediate resuscitation. Although acute renal and respiratory failure was significant, the patient recovered at day 10 after the event, and his liver function and other organ functions were improved. Then, the scheduled left hepatectomy with caudate and extrahepatic duct resection was successfully performed without issues. The patient exhibited no allergic response against the administration of antibiotics or other drugs and the postoperative course was uneventful. The patient was discharged
\end{abstract}


on day 17. The tumor was diagnosed as stage III intrahepatic cholangiocarcinoma and R0 resection was accomplished. Preoperative management, including the liver functional loading test, should be carefully carried out before major hepatectomy.

(C) 2019 The Author(s)

Published by S. Karger AG, Basel

\section{Introduction}

In the field of hepatic surgery, the functional liver reserve is usually precisely examined before hepatectomy to avoid post-hepatectomy liver failure, particularly for major hepatectomy. In Japan, the indocyanine green (ICG) test has been widely applied as the gold standard test even in patients with Child-Pugh class A disease [1]. According to this parameter, the extension of hepatectomy is limited [2]. This preoperative test has recently been applied to detect the existence of liver tumors as the photodynamic eye test [3]. Administration of ICG is supposed to be safe even in patients with a chronically injured liver; however, although anaphylaxis from ICG has rarely been reported, it may lead to severe organ damage [4]. We herein report a successfully resected case of primary intrahepatic cholangiocarcinoma with severe anaphylactic shock leading to organ failure at the time of the preoperative liver test before hepatectomy.

\section{Case Report}

A 65-year-old male patient without epigastralgia was diagnosed with intrahepatic cholangiocarcinoma with peripheral biliary obstruction. He had no remarkable coexisting disease and no history of allergic reactions. The physical examination showed no abnormalities and laboratory data demonstrated liver dysfunction. At the time of admission, increased serum levels of aminotransferase enzymes (aspartate aminotransferase $90 \mathrm{IU} / \mathrm{L}$, alanine aminotransferase $157 \mathrm{IU} / \mathrm{L}$ ) and alkaline phosphatase (1,535 IU/L; normal range <325 IU/L) were observed, but the bilirubin level was normal (total bilirubin $1.0 \mathrm{mg} / \mathrm{dL}$ ). The serum level of carcinoembryonic antigen was increased to $21.4 \mathrm{ng} / \mathrm{mL}$ (normal range $<5 \mathrm{ng} / \mathrm{mL}$ ). The liver uptake ratio at $15 \mathrm{~min}$ by technetium-99m galactosyl serum albumin (99m Tc GSA) was within the normal range at 95\% [5]. Cardiorespiratory and renal function was almost normal (BUN $10 \mathrm{mg} / \mathrm{dL}$, creatinine $0.7 \mathrm{mg} / \mathrm{dL}$ ).

Contrast-enhanced computed tomography (CT) revealed a $2.2-\mathrm{cm}$ irregular low-density space-occupying lesion at the left hepatic duct with obstructive dilation of the peripheral biliary trees (Fig. 1). Although endoscopic biliary drainage was performed, no allergic reactions to the contrast medium for imaging analysis were observed. The ICG test was routinely carried out; however, the patient immediately exhibited unconsciousness and cardiorespiratory arrest due to anaphylaxis from ICG administration. Resuscitation was rapidly performed and consciousness was recovered at $34 \mathrm{~min}$ after resuscitation. The serum BUN and creatinine levels were markedly increased (BUN $36 \mathrm{mg} / \mathrm{dL}$, creatinine $2.6 \mathrm{mg} / \mathrm{dL}$ ), the urinary volume was decreased to $60 \mathrm{~mL}$ per $24 \mathrm{~h}$, and arrhythmia was observed. By management in the intensive care unit using inotropic agents, an artificial ventilator, and diuretic treatment, the patient recovered at day 10 after the event.

Liver function and other organ functions were rapidly improved (BUN $17 \mathrm{mg} / \mathrm{dL}$, creatinine $0.9 \mathrm{mg} / \mathrm{dL}$, total bilirubin $0.7 \mathrm{mg} / \mathrm{dL}$, and alkaline phosphatase $1,694 \mathrm{IU} / \mathrm{L}$ ), and the scheduled left hepatectomy with caudate and extrahepatic duct resection was successfully 
performed (operating time $9 \mathrm{~h} 32 \mathrm{~min}$, blood loss 1,190 mL). The patient demonstrated no allergic response to the administration of antibiotics or other drugs and the postoperative course was uneventful. The patient was discharged at day 17. Histologically, the tumor was diagnosed as stage III intrahepatic cholangiocarcinoma and R0 resection was accomplished.

\section{Discussion/Conclusion}

The ICG test is supposed to be a safe and reliable liver function test in Japan $[1,6]$, and this test is easily performed not only as a preoperative test but also for photodynamic diagnosis during operations [3]. On the other hand, anaphylactic reactions have been previously reported [4], but the prevalence is very low. In our experience, only 1 case out of approximately 650 cases exhibited mild hives. Although this patient had no allergic reactions to the contrast medium for imaging analysis, he exhibited anaphylaxis from ICG testing. Olsen et al. [7] reported a case of anaphylactic shock following ICG angiography in a patient without iodine allergy, so we should keep in mind that serious allergic reactions to ICG may occur with or without iodine allergy.

Allergic responses seem to vary, and in the present case, the patient developed renal and respiratory failure once in a critical situation. Fortunately, he recovered within 1 week. Although abandoning the scheduled major hepatectomy was a concern due to multiorgan injuries by cardiac arrest and anaphylactic shock, his systemic condition was recovered. By recalling this event, it is necessary to check for allergic shock after administration in cases with ICG testing.

Preoperative problems or coexisting diseases may affect postoperative complications. 99mTc GSA is as reliable a liver function test as the ICG test, and GSA is a safe drug [5]. Allergic reactions have not been reported yet. This test showed the distribution of active and living hepatocytes. Previous reports have demonstrated that the liver uptake ratio from ${ }^{99 \mathrm{~m} T c}$ GSA scintigraphy could be converted into an ICGR15 value even in cases of obstructive jaundice [8]. Therefore, patients with a history of allergy can be evaluated with this reliable test, although the cost is high compared with the ICG test.

In conclusion, preoperative management, including the liver functional loading test, should be carefully carried out before major hepatectomy.

\section{Statement of Ethics}

The authors have no ethical conflicts to disclose.

\section{Disclosure Statement}

The authors have no conflicts of interest to declare. 
Higuchi et al.: Anaphylaxis from Preoperative ICG Test

\section{Author Contributions}

K. Higuchi and A. Nanashima wrote this paper. N. Imamura, K. Yano, and Y. Tsuchimochi performed the surgery and perioperative management. M. Hiyoshi, T. Hamada, T. Wada, K. Tsuchiya, F. Kawano, T. Ikeda, and S. Takeno contributed to the patient's care.

\section{References}

1 Schneider PD. Preoperative assessment of liver function. Surg Clin North Am. 2004 Apr;84(2):355-73.

2 Yamamoto Y, Ikoma H, Morimura R, Konishi H, Murayama Y, Komatsu S, et al. Clinical analysis of anatomical resection for the treatment of hepatocellular carcinoma based on the stratification of liver function. World J Surg. 2014 May;38(5):1154-63.

3 Abo T, Nanashima A, Tobinaga S, Hidaka S, Taura N, Takagi K, et al. Usefulness of intraoperative diagnosis of hepatic tumors located at the liver surface and hepatic segmental visualization using indocyanine greenphotodynamic eye imaging. Eur J Surg Oncol. 2015 Feb;41(2):257-64.

4 Speich R, Saesseli B, Hoffmann U, Neftel KA, Reichen J. Anaphylactoid reactions after indocyanine-green administration. Ann Intern Med. 1988 Aug;109(4):345-6.

5 Wu J, Ishikawa N, Takeda T, Tanaka Y, Pan XQ, Sato M, et al. The functional hepatic volume assessed by 99mTc-GSA hepatic scintigraphy. Ann Nucl Med. 1995 Nov;9(4):229-35.

6 Kubota K, Makuuchi M, Kusaka K, Kobayashi T, Miki K, Hasegawa K, et al. Measurement of liver volume and hepatic functional reserve as a guide to decision-making in resectional surgery for hepatic tumors. Hepatology. 1997 Nov;26(5):1176-81.

7 Olsen TW, Lim JI, Capone A Jr, Myles RA, Gilman JP. Anaphylactic shock following indocyanine green angiography. Arch Ophthalmol. 1996 Jan;114(1):97.

8 Kawamura H, Kamiyama T, Nakagawa T, Nakanishi K, Yokoo H, Tahara M, et al. Preoperative evaluation of hepatic functional reserve by converted ICGR15 calculated from Tc-GSA scintigraphy. J Gastroenterol Hepatol. 2008 Aug;23(8 Pt 1):1235-41.
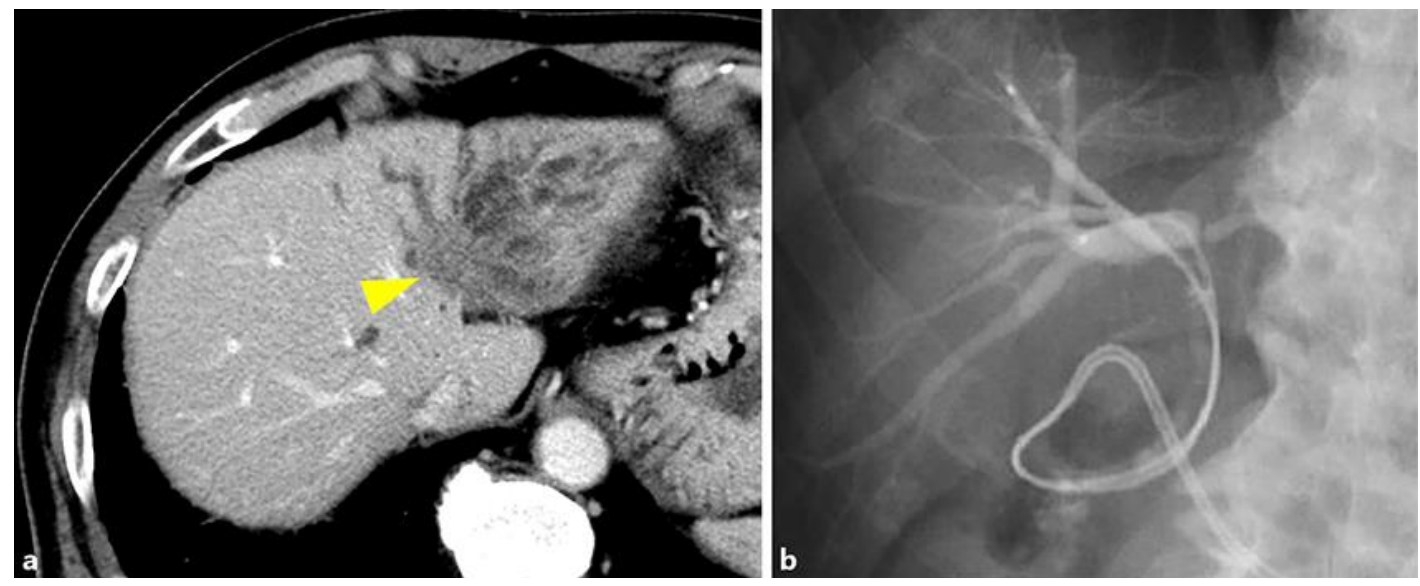

Fig. 1. a, b Enhanced CT with contrast medium and endoscopic cholangiography showed a low-density mass-forming lesion in the left liver obstructing the left hepatic duct (arrowhead). Left hepatectomy was scheduled following this imaging finding. 